\title{
Experiences of handwriting and using a computerized ATD in school: Adolescents with Asperger's syndrome
}

Ingrid Breivik and Helena Hemmingsson

\author{
Linköping University Post Print
}

\section{Tweet}

N.B.: When citing this work, cite the original article.

Original Publication:

Ingrid Breivik and Helena Hemmingsson, Experiences of handwriting and using a computerized ATD in school: Adolescents with Asperger's syndrome, 2013, Scandinavian Journal of Occupational Therapy, (20), 5. http://dx.doi.org/10.3109/11038128.2012.748822

Copyright: Informa Healthcare

http://informahealthcare.com/

Postprint available at: Linköping University Electronic Press http://urn.kb.se/resolve?urn=urn:nbn:se:liu:diva-93215 


\section{Experiences of handwriting and using a computerized ATD in school: adolescents with Asperger syndrome}

Corresponding author:

Ingrid Breivik,

reg. OT, Msd, Ccs. OT

Children and Youth Habilitation Centre

Östersund Hospital

Jämtland County Council

Phone: +46 63154632

Fax: $\quad+4663154523$

E-mail: ingrid.breivik@jll.se
Second author

Helena Hemmingsson

Professor, reg.OT, PhD

Dep. of Social- and Welfare Studies (ISV)

Faculty of Health Sciences

Linköping University

60174 Norrköping, Sweden

E-mail: helena.hemmingsson@liu.se 


\begin{abstract}
Adolescents with Asperger syndrome, AS, often have handwriting difficulties which affect their academic performance. The purpose of this descriptive multiple case mixed method study was to highlight how adolescents with AS experience writing in the school setting when writing by hand and when using a computerized Assistive, Technology Device, ATD, for writing. A qualitative content analysis approach was used, including interviews with five adolescents, their parents and their teachers. This was complemented by asking the adolescents to rate their perceived performance and satisfaction of writing with and without the ATD. All adolescents described handwriting difficulties, but a reduced ability to express oneself in writing was also common. Initiating and completing writing tasks was often so demanding that it caused resistance to the activity. Several advantages when using the ATD were described by the participants and the self-ratings showed higher scores for performance and satisfaction of writing when the ATD was used. The results show that teachers' encouragement seemed to be important for the initiation and continuation of use of the ATD.
\end{abstract}

Keywords: case reports, disabled children, mainstreaming education, handwriting, self-help devices, consumer satisfaction 


\section{Introduction}

One of the most important occupational performance skills that children learn in school is to write legibly by hand $(1,2)$. Children with developmental disorders often struggle for years learning this skill $(1,2,3)$. Handwriting requires good visual-motor coordination and cognitive and perceptual abilities $(4,5)$. Shaping individual letters and detailed and complex sequences of letters requires intact motor planning $(1,5)$. To write a composition an idea about content and an ability and an ambition to initiate and fulfill the task is also important. Through writing the child is able to express knowledge (4) and poor writing skills interfere with academic achievement and social interaction (2), which limits participation in daily schoolwork.

Autism Spectrum Disorders, ASD, are a range of related disabilities with similar characteristics. One of these disabilities is Aspergers Syndrome, AS (6. 7. 8).

Children with AS have normal intellectual capacity (6), but show linguistic and motor control difficulties, limitations in social interaction and often develop restricted, repetitive patterns of behavior, interests and activities $(7,8,9)$. A recently conducted scoping review on handwriting difficulties in children with Autism Spectrum Disorders, ASD, found altogether six studies, of which two specifically addressed handwriting difficulties in children with AS (10). The review concluded that diminished overall legibility and letter formulation are points of convergence among existing studies of handwriting quality in children with ASD.

Handwriting difficulties, are one of the most common reasons for the referral of school children to occupational therapy both in Sweden and internationally $(3,5,11)$. Previous research on handwriting difficulties among children with motor disabilities, including 
children with AS, has often been based on observations and has focused on motor function $(2,4,5,12,13,14)$. So far evidence that kinesthetic or sensory motor based training substantially improves handwriting is lacking. Of that reason computer keyboarding has been suggested as a compensatory approach (2).

Preminger et al (2) points out several advantages that keyboarding as an alternative to handwriting gives children with handwriting difficulties, for instance that the writing process becomes more effective and the output more legible (2). In a study in which typically children participated they found that keyboarding and handwriting might require different skills of the child, which shows that use of a computer could be an alternative writing method for schoolchildren with handwriting difficulties. Rogers and Case-Smith (12) found that handwriting speed and legibility among typically developing students showed low to moderate relationships with keyboarding speed. They keyboarded faster than they wrote by hand and most participants who wrote slowly by hand and those with poor legibility increased quantity and legibility when they keyboarded (12). It was suggested that keyboarding made different demands on motor planning, motor perceptual skills, visualmotor integration, visual memory and cognitive planning than handwriting. Moreover, computer keyboarding might change the students' attitude in a positive direction by compensating for motor difficulties, thereby increasing students opportunities to express their thoughts and knowledge $(2,12)$. This may indicate that computer keyboarding is preferable to handwriting depending on the child's age and type of writing difficulties. Neither Preminger et al (2) or Rodgers and Case Smith (12) addressed children with AS in their study. Research is still scarce and the development of typing proficiency among students with handwriting problems needs further study (15). 
To conclude, research is limited on handwriting difficulties among schoolchildren and adolescents with AS and on how they may benefit from keyboarding. It was believed that a research approach, that addresses adolescents with AS themselves would give an indication of how they experience writing in the school environment and thus this study was devised. The aim of this descriptive multiple case mixed method study was to highlight how adolescents with AS experience writing in the school setting when writing by hand and when using a computerized Assistive Technology Device, ATD, for writing.

Performance in an activity depends on the individual's skill, motivation and routine and is a dynamic interplay between the individual and the context (16). The individual receives feedback from the surrounding environment and conditions are created which affect motivation, choice of activities and performance. Therefore not only adolescents with handwriting difficulties participated in this study, but also their teachers and parents.

\section{Materials and methods}

This study was approved by The Ethical Committee at Umeå University, Umeå, Sweden.

\section{Design}

A descriptive multiple case mixed study method was used that adopted a predominantly qualitative approach (17). Qualitative interviews with adolescents, parents and teachers were the main basis of the data collection. In order to provide the adolescents with AS with an additional way to express themselves, as a complement they rated perceived performance and satisfaction of writing A) in handwriting and B) when using the device (17). In order to look 
for variations in perceptions of individuals not just one case was studied, but five $(17,18$, 19).

The ATD

The chosen ATD was an Alpha Smart Neo, a portable keyboard with a display that clearly shows what is written (www.alphasmart.com). No log in is necessary and one has access to eight files which can be offloaded to a personal computer for necessary formatting. It can easily be handled by the student who can connect it to a printer to give the teacher the produced text when needed. In the following quotations the Alpha Smart is referred to as "the device".

\section{Participants}

\section{Selection}

Adolescents were recruited from the Children and Youth Habilitation Centre of a northern county of Sweden. The study included adolescents with AS who A) were between 11 - 16 years of age, who through earlier occupational therapy assessment had documented limited hand function and handwriting difficulties in school, and B) had used the computerized ATD for at least one year, and were still using it. Previously, when the children were referred to the Habilitation Centre for assessment, parents and teachers reported severe handwriting difficulties. The parts concerning pure motor function of the Assessment of Children's Hand Function (20), Test of In-Hand-Manipulation (21) and observation of handwriting were implemented during the team examination of the children in order to establish the described difficulties. The age group in the study was chosen because they face higher demands for written work than younger groups. The first author who was employed at the Habilitation Centre at the time, made the assessments and thus met the adolescents on one occasion one 
year or earlier before information letters on the study were sent. Parents of all adolescents who had contact with the Habilitation Centre and who met the inclusion criteria and had been prescribed an ATD more than a year previously $(n=16)$, received a letter with information about the study and a request for participation. Seven parents gave their consent, among whom two were excluded because their adolescent no longer used the ATD. The parents who chose not to participate thought their adolescent would be unwilling to take part and answer questions. The five adolescents who met the inclusion criteria received a personally directed request for participation and information about the study. Their teachers were also asked to participate and were informed about the study and their part in it. All adolescents and teachers accepted.

\section{Data collection}

\section{Interviews}

A semi-structured interview guide in four parts was developed that included both open and more structured questions $(18,19)$. The first part of the interview guide contained introduction questions, the second part contained questions about the activity of writing in general in the school setting, the third part contained questions about handwriting, and the fourth part contained questions about writing when using the ATD. The interview guide had three versions, one for the adolescents, one for their parents and one for their teachers. Questions in the interview guide were on the following topics: handwriting, attitude to writing, learning to write by hand, instructions, writing tasks, starting writing, keeping up writing, ideas on what to write about, favourite subjects, disliked subjects, learning to write using the device, usage of the device. Examples of questions to the adolescents are:

How are you told when and what you must write about in school? How do you solve a writing task that the class receives? What do you like to write about? What do you not like to write about? On what 
occasions do you write by hand? How did you to learn to write on the device? On what occasions do you use the device?

Questions to the parents included:

How does he/she solve a writing task that the class receives? How well do you think your child has learned to write? Can you please describe your child's attitude towards writing in general? What does he/she like to write about? What does he/she not like to write about? Does he/she use paper and pencil or the device? How did your child learn to use the device?

Questions to the teachers included:
How does he/she solve a writing task that the class receives? Can you please describe his/her attitude towards writing in general? Do you have any strategies to help him/her and if so, can you describe them? Does he/she use paper and pencil or the device? How did he/she learn to use the device? Do you encourage him/her to use the device?

In this paper writing is referred to as an activity which is performed by hand or by the ATD.

\section{Ratings of performance and satisfaction of writing}

Children with AS often interpret what other people say literally and lack the ability to converse (7). Because of qualitative impairment in social interaction (9) they are sometimes unable to speak themselves or do so much later than other people. Bearing in mind that linguistic and communication difficulties like these are common among people with AS, a . A ten point rating scale was used to complement the interviews. The rating scale from the Canadian Occupational Performance Measure, COPM, (22), was used when the adolescents were asked to estimate how they perceived their performance and satisfaction of writing A) in handwriting and B) when using the device, to look for differences between scores for the two writing ways. The use of the ten points rating scale where higher scores reflect better 
performance and satisfaction, presented an alternative and more structured way for the adolescents to evaluate their writing. The COPM has shown to have good validity for clients with a variety of disabilities (23) and has earlier been used with boys aged 10 and 12 years with AS (24), and with high school students with autism (25). According to the COPM manual a change of two or more points is considered clinically relevant (22).

\section{Procedure}

Interviews were booked in and carried through individually with adolescents, parents and teachers. In each triad the adolescents were interviewed first followed by either the parent or the teacher. The time and place for the interviews were either in the school setting or in the premises of the Habilitation Centre, depending on the interviewees' wishes. Each interview lasted about 45 minutes and was taped. After being interviewed the adolescents were asked to rate their performance and satisfaction regarding writing with and without the device.

\section{Data analysis}

All interviews were written out verbatim and the qualitative content analysis was carried out in four stages (26). During the first stage all interviews were read through to get an overview of the collected material and to identify themes. In stage two the texts were analysed one by one, and then condensed into meaning units that captured the writing experience. These units were abstracted into codes which were chosen based on the overall impression of the interviews and the main aim of the study. Comparisons with the text as a whole were made throughout. In the third stage the meaning units and the codes from the second phase were condensed and sorted into categories to structure the material and to obtain a general view. The categories were chosen based upon the content of the different meaning units and the aim of the study. The material that emerged around each adolescent was analysed in the fourth 
phase and summarized into five individual cases. Each participating family received a summary of their case to validate, and every family ratified their case (18). In the fourth stage the five cases were cross-case analysed $(17,18)$. They were simultaneously compared to identify similarities and differences. Answers from the five cases were compared and put together into clusters and important data was found from which categories were created that represented all five. When compared, the content of each category within the cases corresponded to the original text, confirming that the chosen categories reflected the content in the interviews $(17,18)$. Scores from the adolescents' ratings were analysed and put into figures $(17,18)$. To increase the credibility of the analysis peer examination was carried out throughout the analysis by a tutor with academic and research experience (27).

\section{Results}

Four boys and one girl participated, reflecting the fact that more boys than girls are diagnosed with AS (8). Participating adolescents attended regular classes in their neighbourhood school. The parents and teachers were all women. In total fifteen persons participated in the study. Analysis of the five cases gave the mutual categories writing difficulties, feelings towards writing, learning context and the use of the ATD, which are included in the presentation of each case $(17,18)$. The result of the ratings of perceived performance and satisfaction of writing A) in handwriting and B) when using the device, matched the qualitative data, on how the performance of writing was experienced. This triangulation indicates the trustworthiness of the result $(17,18)$.

The cases 
Pseudonyms were used for the adolescents in the presentation of the cases. This presentation is followed by the adolescents’ ratings of experienced occupational performance and satisfaction of writing performance by hand and using the ATD.

\section{Joseph, 13 years}

Joseph only writes by hand occasionally and he is not satisfied with his performance. He explains that he pushes the pencil so hard that his hand hurts. Initiating writing is difficult and he rarely manages to finish a task within the time limit. According to his teacher this is because he is a slow hand writer with letter shaping difficulties and concentration problems. His motivation is greatly affected by his temper and whether or not he is having a good day. Joseph expresses an aversion to handwriting, as the following quote illustrates:

It is a bit tiresome to write sometimes. Sometimes I get very angry and don't want to work. Or do this rubbish, and I throw things around and that is not so good. I'd then rather do something else, like in the English lessons I want to pull out a book that I have and sit and read, or when it gets boring.

He likes history and can start writing from the beginning of those lessons. Joseph often uses the ATD, mostly when he writes longer texts and works on projects. He thinks it is important to have it within reach, as it is easier for him to write on it than to use paper and pencil and because he avoids pain in his hand when using it. His teacher sees it as great alternative to the computer because he can carry it with him and use it wherever he wants.

\section{Andrew, 16 years}

According to his mother Andrew has always found handwriting difficult and he writes almost illegibly. He never writes anything by hand except for vocabularies and short notes. He describes the situation as follows:

The teacher stands at the front and tells us that now we are going to write, I suppose. When we write I can 
use my typewriter, or they copy someone else's notes. I write either with paper and pencil or on the device, depending on the task

His teacher explains that his composition writing works best when she has time to discuss his thoughts with him in advance. There are not enough resources available to give Andrew the amount of individual support he really needs to initiate and to organize his writing. He has difficulties getting started and sometimes he does not manage it at all, especially when he is supposed to write freely and analyze feelings, thoughts and dreams. He spends a lot of time thinking through what he is going to write beforehand, making writing tasks time consuming for him. He explains:

I think it over first, and then I write. You just start and then you continue from there. If you don't come up with anything you just choose the first thing you think of. Or you don't write at all. Sometimes I have to think for a long time.

Andrew found it easy to learn to write using the device as he could already write on a computer. He describes himself as extremely good at using the device and points out that it works well when he writes texts and national exams, but less well when he does mathematics and tasks in social subjects and science. He says:

I use the device for everything it can possibly be used for. I write examinations and short stories, tales, compositions and tasks. I use the device in school, whenever possible. There is enough time when I write on it.

The teacher explains that the ATD enables her to read what Andrew writes and because of that she sees the device as a necessary tool for both him and her.

\section{Alyssa, 15 years}


Alyssa is reluctant to write by hand and only does so occasionally to take notes, write vocabularies or scrawl. She says:

If I write by hand a lot I get a pain in my little finger for some reason. Noooo, and I get tired and it is tiresome and (sighs), ugh! I know, but I don't know why I get a pain in my little finger. If I'm supposed to write a composition I use the device. I still do not keep up though, but it is quicker than writing by hand.

Both thinking and expressing herself is energy consuming for Alyssa. Writing by hand makes her physically tired. It is easier when she writes about a subject she likes and when she gets help to organize her writing without too exact terms of reference. She has always had difficulty producing text and she has extremely high demands on the result. It is hard for her to finish in time, especially during exams, because she can get stuck on one particular wording and then the writing progresses very slowly. She emphasizes how difficult it is to start writing, and she prefers not to write at all. She feels frustrated and stresses that it is not what she is supposed to write about that is the problem, rather the fact that she is expected to write at all. She says:

It is important because in today's society you cannot manage without being able to write. Do you really think that you can get an employment if you come in with your CV and it says: weaknesses: Cannot write! Then I don't think you get a job.

Alyssa writes faster on the device than by hand and thinks the spelling program is good. Her mother says Alyssa was proud when she got the device, but was disappointed when she later realized that it did not compensate for her difficulties with formulation. She now feels that the device makes her stand out and does not want her classmates to see it. The teacher often encourages her to use it, but she is adamant not to.

\section{Thomas, 13 years}


Thomas describes that writing by hand and shaping letters is very time consuming for him. His mother says that his handwriting is hard to read despite him writing slowly. When writing by hand he expresses himself briefly and does not achieve the content in his writing that he would like. Due to his motor difficulties it takes a great deal of effort for Thomas to write by hand. He says:

I can usually start well, except when I write by hand, then it is a bit hard. If I am supposed to write a story, I am big fan of Star Trek, I write. Right now I am writing a story in English about Star Trek and one in both English and Swedish.”

His teacher describes that both initiating and continuing to write is easier for Thomas when using the ATD. He used to hate writing, but now since he has access to the ATD, he writes everything in all subjects. When allowed to choose what to do in school he often chooses to write a story, which he never did before. His mother explains that it is easier for him to correct errors on the ATD and that he never would have the patience to change and increase his compositions in the same way if he wrote by hand. He was embarrassed by the ATD at first, and chose not to use it in the classroom. Today it is a necessary tool for school work and he uses it in all subjects. He says about writing a composition:

I don't want to write about love and romance, you see, that is so boring. If I can manage it depends on if I am allowed to write on the device. I don't work very often by hand when we are supposed to write, because then I choose the device.

Through daily encouragement to use it as often as possible, his teacher has downplayed the usage of the ATD. She writes clearly on the board what is to be done and why, and whether he should write on the device or in his work book.

\section{Ryan, 11 years}


According to Ryan's mother it took Ryan a long time to learn handwriting. His teacher explains that he strains his hand and arm and presses heavily on the pencil when shaping letters. He has difficulties coming up with ideas on what to write about and needs to be given a clear reason as to why he should do it, otherwise he finds it meaningless. Often he cannot mobilize power to write by hand. He becomes bored and spends time scribbling or doodling instead. He says:

But there must be a story and a beginning and an end. Otherwise it does not work. For example when we made up a story where we were supposed to draw and write the last page. That was no good, because it was totally white on that page then. I did not write anything, Well, I scribbled a lot, I did. I could not work out how to move on.

Ryan gets frustrated over not being able to get started. He finds it difficult to focus on writing when he is not in the mood, which is closely related to his current daily shape. His teacher describes how hard it is to motivate him then, he can get stuck playing with his rubber, sucking on his pencil or fiddling with scraps of paper. It works best when he can write about his interests, but then he wants the result to be perfect and erases a lot. He found it easy to learn to write on the ATD. He writes faster, can endure writing for longer periods of time and manages to keep up quite well. Spelling is also easier. He says:

\footnotetext{
I can't think of anything bad with the device, no I don't know. Most things are good, for example that you can change files instead of going to fetch a new paper and so on. You just push a button and then you have a new file. Then you can erase the files too, which you can't on a paper. It is good that it doesn't get messy when you erase on the device. That is good.
}

His mother remembers that he felt special when he first got the device, that he had something that no one else had.

\section{Ratings of experienced occupational performance and satisfaction}


The figures show comparisons between the adolescents' experiences of writing by hand and using the device. Fig. 1 shows that four of the five adolescents, all the boys, experienced that writing worked better when they used the device than when they wrote by hand. The girl, Alyssa, rated her perceived writing performance slightly better $(0,5 p)$ when she used the device. Fig. 2 shows that Joseph, Andrew and Thomas were more satisfied with their writing when they wrote on the device than when they wrote by hand. Alyssa rated satisfaction one point higher when writing by hand than when using the device. Four of the five adolescents, all the boys, rated writing performance two or more points higher when using the device than when writing by hand. Three of them, Joseph, Andrew and Thomas, rated satisfaction of writing performance two or more points higher when using the device than when writing by hand.

\section{Discussion}

This study gives an insight into how writing can be experienced by adolescents with AS. The participating adolescents described several aspects of handwriting difficulties concerning letter shaping problems combined with pain in the hand and fingers. In addition, and especially the girl, Alyssa, all cases described difficulties coming up with ideas on what to write about and difficulties with wording. A lack of motivation to start up and follow through with the writing task was also common. The ATD was perceived to contribute to compensation mainly for motor difficulties and when using the device writing became readable, land less time consuming and more extensive texts were written. Pain was avoided and performance speed increased. The participants also mentioned the advantages of being able to keep up with classmates, and being able to make changes in the text easily, being able to change files and use the spelling program. 
Access to the device contributed to a positive attitude towards writing which was also performed more frequently, especially by Andrew and Thomas. The use of the ATD seemed to encourage a positive writing development which increased opportunities to express knowledge and complete academic tasks. This in turn indicates to lead to a positive effect on self-esteem and self-confidence among the students as suggested by several researchers $(1,2$, $3,4,11)$.

Including parents and teachers in the interview part gave a varied picture of how the writing was performed in the school setting. Combining qualitative interviews and the adolescents' own ratings of their perceived performance and satisfaction of writing A) in handwriting and B) when using the device gave broad information. The scores from the COPM (19), supplemented the five cases and clarified their content.

Generalization of the results to other computerized ATDs than the device examined in this study may be questioned. The benefits of keyboarding, spelling programs, easiness to erase and change texts are present in most computerized writing devices and described in earlier research $(2,12)$. However, the ATD used in the current study has the advantages of low cost and easiness to move and handle. Press \& Banton, 2007 emphasized the importance of considering the student's ability to independently set up, create and reopen a file the next lesson when selecting a portable word processor (28). Their research showed the best solution to be the simplest device that provides access to an activity. Thus, although many computerized ATDs share advantages, other important aspects such as size and ability to use it independently in different settings are important to consider and may influence the young person's readiness to use the ATD. Further research is needed to clarify this issue. 
However, teachers, peers and school staff also play an important role in how an ATD is received. Teachers' encouragement to use the device was important in the present study and supported the use of the ATD. All but one of the adolescents, Andrew, were dependent on the teachers' encouragement to use the device in the school setting. The adolescents depended on the teachers being positive and encouraging the use of the ATD, and this seemed to be a condition for the students' success. We suggest that teachers are informed on how Thomas' teacher encouraged him positive to take a positive attitude towards the ATD. In terms of implications it could be proposed that teachers do like this teacher did and give direct and clear instructions on when to use the ATD. The teachers' vital role in integrating the ATD in education in order for it to be used effectively has support in earlier research (29, 30). Attitudes among peers also affect the use of ATDs in school (30). In fact, adolescents might prioritize social aspects before educational achievements. In the present study one of the participants, the girl Alyssa, felt different and deviant when using the ATD in front of peers and thus avoided using it in class, despite finding writing to be easier and faster when using it. Thus, social aspects have to be considered when suggesting an ATD, especially if the ATD is to be used in school among non-disabled students (30).

A limitation of this study is that only adolescents who still used their ATD were included. Had adolescents who had given up using the ATD also been included in the study more negative aspects of the use of the ATD could have emerged. However, extensive experience of using the ATD in school and its continued use was considered a necessary condition to examine how the actual ATD influenced students’ writing in school.

Based on the results of this study it is important to remove the barrier to writing that handwriting represents to children and adolescents with AS, to make it easier for them to 
perform and develop the activity. One suggestion is that the occupational therapist carefully informs teachers and parents about the specific writing difficulties common among children and adolescents with AS and the advantages that an ATD can present. The children and adolescents need support and strategies to develop their ability to express themselves in writing and getting access to a computerized ATD in school seem to be a promising strategy. Because of the limited sample size in this study it is difficult to generalize the result. Further studies with larger samples are needed to clarify which support and which type of ATD that children and adolescents with AS may benefit from. More research is also required regarding occupational therapists role and support concerning the performance of school activities.

\section{Acknowledgements}

The authors would like to thank the participating adolescents, their parents and teachers. 


\section{References:}

1. Cunningham Amundson S. Handwriting: Evaluation and intervention in school settings. In:Case-Smith J, Pehoski C, ed. Development of hand skills in the child. Rockville: MD American Occupational Therapy Association, 1995:63-78.

2. Preminger F, Weiss P L, Weintraub N. Predicting occupational performance: Handwriting versus keyboarding. Am J Occup Ther 2004;58:193-201.

3. Hammerschmidt S L, Sudsawad P. Teachers' survey on problems with handwriting: referral, evaluation, and outcomes. Am J Occup Ther 2004;58:185-192.

4. Maeland A E. Handwriting and perceptual motor skills in clumsy, dysgraphic and normal children. Percept Mot Skills 1995;75:1207-1217.

5. Rosenblum S, Goldstand S, Parush S. Relationships among biomechanical ergonomic factors, handwriting product quality, handwriting efficiency, and computerised handwriting process measures in children with and without handwriting difficulties. Am J Occup Ther 2006;60:28-39.

6. Wing L, The Autistic Spectrum - A Guide for Parents and Professionals, Robinson Publishing, London, 2003.

7. Attwood T, The Complete Guide to Asperger's Syndrome, Jessica Kingsley Publishers Ltd, London, 2007. 
8. Gillberg C, Peeters T. Autism: Medical and Educational Aspects, 2nd ed. Whurr Publishers Ltd, London; 1999.

9. American Psychiatric Association, Diagnostic and statistical manual of mental disorders (DSM-IV-TR), Washington DC:APA, 2000.

10. Kushki A, Chau T, \& Anagnostou E. Handwriting Difficulties in Children with Autism Spectrum Disorders: A Scoping Review, J Autism Dev Disord. 2011;41:1706 1716.

11. Cermak S A. Fine Motor Functions and handwriting. In: Fischer A G, Murray E A, Bundy A C, ed. Sensory Integration: Theory and practice. Philadelphia: F A Davis Company; 1991:166-70.

12. Rogers J, \& Case-Smith J. Relationships Between Handwriting and Keyboarding Performance of Sixth-Grade Students. Am J Occup Ther 2002;56:34-39.

13. Sudsawad P, Trombly C A, Henderson A, Tickle-Degnen L. Testing the effect of kinaesthetic training on handwriting performance in first grade students. Am J Occup Ther 2002;56:26-33.

14. Denton P L, Cope S, Moser C. The effects of sensorimotor-based intervention versus therapeutic practice on improving handwriting performance in 6- to 11-year-old children. Am J Occup Ther 2006;60:16-27. 
15. Freeman R A, McKinnon J R, Miller L T. Assistive technology and handwriting problems: what do occupational therapists recommend? Can J Occup Ther 2004;71:150-160.

16. Kielhofner G. A Model Of Human Occupation, Theory and Application. Baltimore: Lippincott \& Wilkins, 2002.

17. Creswell J. Research Design. Qualitative, Quantitative and Mixed Methods Approaches. Thousand Oaks: Sage Publications Inc, 2002.

18. Merriam S B. Case Study in research education: a qualitative approach. San Francisco, California: Jossey Bass, 1998.

19. Patton, M. Q. Qualitative Research and Evaluation Methods. Thousand Oaks: Sage Publications Inc, 2002.

20. Jacobsson H, Sundquist A, Handfunktionsbedömning på barn från 6 år. Falun: AB Allnor Kopiering, 1998.

21. Exner C, Development of hand functions, In: Pratt P, Allen A, ed. Occupational Therapy for children, Baltimore: Mosby, 1989.

22. Law M, Baptiste S, Carswell A, McColl M A, Polatajko H, Pollock N. Canadian Occupational Performance Measure (2nd ed.). Ottawa: CAOT Publications ACE, 1998. 
23. Dedding C, Cardol M, Eyssen CJM I, Beelen A. Validity of the Canadian Occupational Performance measurement. Clin Rehabil 2004;18:660-667.

24. Rodger S, Ireland S, Vun M. Can Cognitive Orientation to daily Occupational Performance (CO-OP) help Children with Asperger's Syndrome to Master Social and Organisational Goals? Br J Occup Ther 2008;71:23-32.

25. Gentry T, Wallace J, Kvarfordt C, Lynch K B. Personal digital assistants as cognitive aids for high school student with autism: Results of a community-based trial. J Vocat Rehabil. 2010;32:101-7.

26. Graneheim U H, Lundman B. Qualitative content analysis in nursing research: concepts, procedures and measures to achieve trustworthiness. Nurse Educ Today 2004; 24:105-112.

27. Bogdan RC, and Biklen SK. Qualitative research for education: An introduction to theory and methods. Boston: Allyn and Bacon, 2003.

28. Press M, \& Banton A. Technology Solutions for Struggling Writers. Technology Special Interest Section, 2007;17:1-4.

29. Derer K, Polsgrove, L, Rieth H. A survey of assistive technology applications in schools and recommendations for practice. Journal of Special Education Technology, 2006;XIII:62-80. 
30. Hemmingsson H, Lidström $\mathrm{H}$, \& Nygård L. The use of assistive technology devices in mainstream schools: the students' perspective. Am J Occup Ther 2009;63: 461-470. 


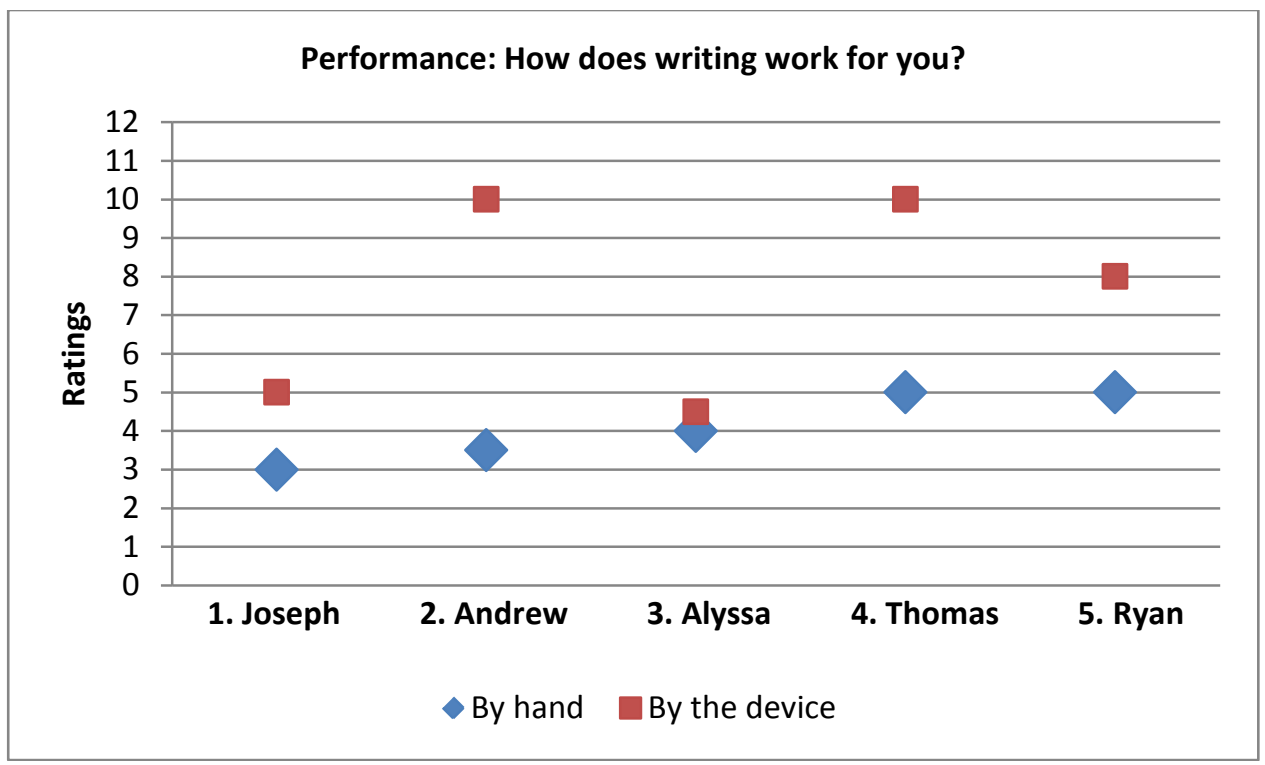

Figure 1. Participants' ratings of perceived writing performance, by hand or by using the device.

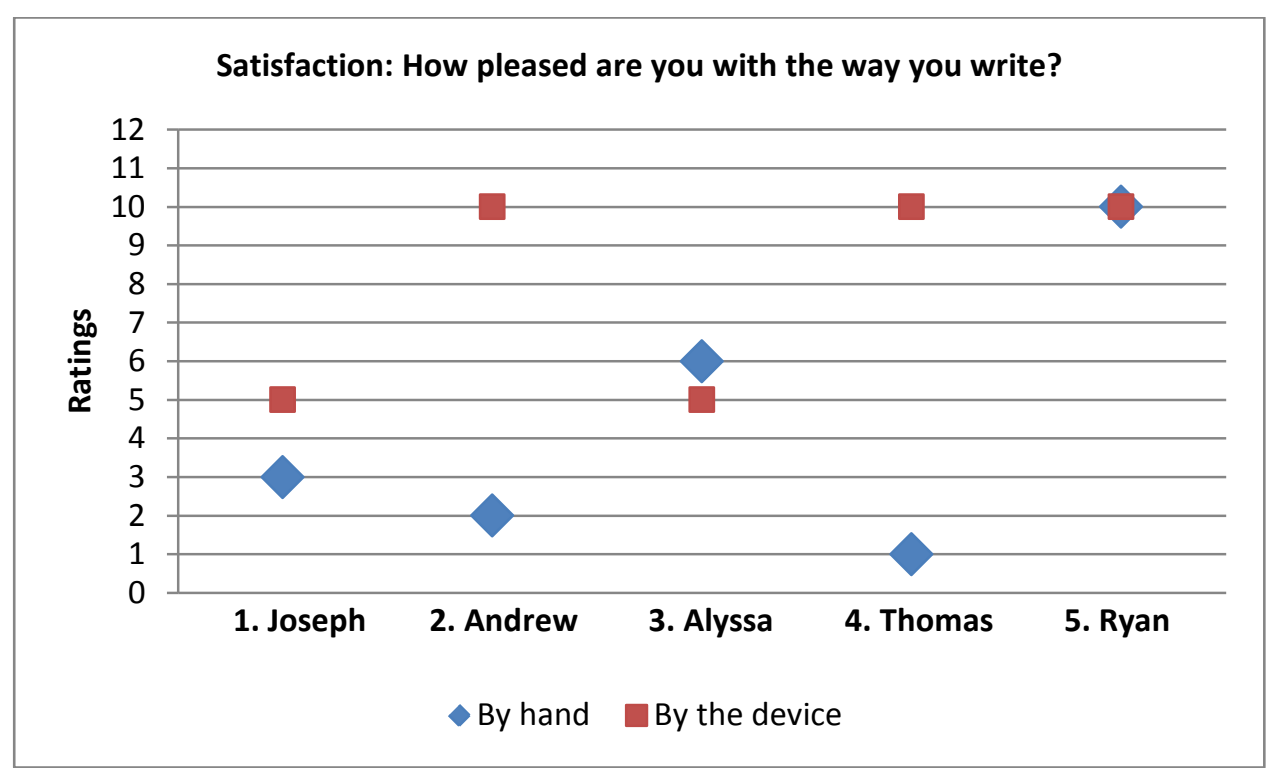

Figure 2. Participants'ratings of perceived satisfaction of writing performance, by hand or using the device. 